\title{
Papillary fibroelastoma of posterior mitral leaflet, confused as vegetation or calcification
}

\author{
Hemant Chaturvedi ${ }^{1}$ \\ ${ }^{1}$ Eternal Hospital and Research Institute
}

November 20, 2020

\begin{abstract}
Cardiac papillary fibroelastoma $(\mathrm{CPF})$ is the most common valvular tumour of the heart and the second most common primary cardiac tumour. Fewer than 50 cases being reported in the literature [1]. As the advancement in 3D echocardiography, its diagnosis in living patient is become easy. The CPF could be found on valve leaflets, chordae tendineae, and both ventricles. We present an interesting case of the CPF originating from the posterior leaflet of the mitral valve confusing with vegetation or annular calcification. The patient underwent successful surgical removal of the PFE
\end{abstract}

Title: Papillary fibroelastoma of posterior mitral leaflet, confused as vegetation or calcification

Authors details:

Hemant Chaturvedi, (first author) Diploma Cardiology, FACC

Head Non-Invasive Cardiology, Eternal hospital, Jaipur (Rajasthan)

Email ID: drhemant.chaturvedi@gmail.com

Correspondent author:

Hemant Chaturvedi, (first author) Diploma Cardiology, FACC

Head Non-Invasive Cardiology, Eternal hospital, Jaipur (Rajasthan)

Email ID: drhemant.chaturvedi@gmail.com

There is no conflict of interest to be disclosed by all authors.

Abstract :

Papillary fibroelastoma (PFE) is one of the most common tumour of heart valves and found to be second common primary cardiac tumour. Only less than 50 cases were reported in the literature [1]. As the advancement in 3D echocardiography, its diagnosis in living patient is become easy. The PFE could be found on both ventricles, valvular leaflets, and chordae tendinea. We present an interesting case of the CPF originating from the posterior mitral leaflet confusing with vegetation or annular calcification. Successful surgical excision was done of the papillary fibroelastoma.

Case Report: A 44years old gentleman admitted with complaints of left arm pain and numbness. His blood pressure, pulse, temperature, and saturation were within normal limits. Labs parameters were normal. 2D echocardiography revealed a mobile mass on posterior mitral leaflet (PML). Further transesophageal echocardiography was done to confirm the findings. It suggested a mobile cardiac mass measured 11X 15 $\mathrm{mm}$ on the PML (P2 scallop) towards left atrium and pedunculated (Fig A). This mobile excrescence was leading to malcoaptation of mitral leaflets with moderate mitral regurgitation (Fig B) also. He received 4 
weeks antibiotic therapy in view of suspected vegetation endocarditis, but this mobile mass was not resolved, and serial blood cultures were negative. The characteristics of the mobile mass, with location, shape size and appearance were likely of papillary fibroelastoma. It was further confirmed with 3D TOE (Fig C\& Fig D), which clearly showed the tumour characteristics. Surgical excision of the mass was planned, and it was removed while preserving the mitral valve. Histopathology examination confirmed the diagnosis of papillary fibroelastoma. The histopathology examination revealed a papillary lesion composed of numerous papillary fronds with an acellular fibro-hialinous stroma. The lesion has an infiltrative-like appearance, but the excisional margin itself was free of neoplasia. (Fig. E and F). Due course of hospital was uneventful, and he was discharged on eighth day in a stable condition.

Discussion: Any previous injury to the endothelium, arise as hamartomatous and organizing emboli are some mechanism which may cause Papillary fibroelastoma (PFE) [2]. PFE can occur in close to injury site If trauma is mechanically induced [3]. Presence of elastin and fibrin fibers in fronds give a clue of PFE origin from organizing thrombi [2]. According to one theory that is microthrombus theory which stresses the fact that these lesions are acquired and they arises as small thrombi that serve as a nidus for further ecrescents to minor endothelial site injury of the valves or to previous diseased valves. Neurological symptoms may occur when PFE located on left sided heart with hamartomatous growth of endocardial tissue. PFE mimics to Lambl's excrescences, but it is larger to cause symptoms due to embolization and coronary ostia occlusion due to prolapse $[4,5]$. Another theory is that PFEs are true tumoral lesions that predominantly affect heart valves. Cardiac myxoma is one of most important differential diagnoses. But In contrast to myxoma, no associated inflammation and vascular structures were found in it. There are many characteristics that can differentiate PFE from thrombus.

[4] and vegetation [5]. PFE is usually found on mid part of valvular leaflets as solitary mass with size less than $1 \mathrm{~cm}$ and frond like peripheral surface. PFE can often be rule out by clinical history, serial blood cultures and lab tests by that reasons only. Although PFEs are benign but acute myocardial ischemia, stroke, thromboembolism and sudden death can be few dangerous complications [6]. PFE on mitral valve leads to systemic embolism more frequently [7]. Surgically excision of PFE is recommended in both symptomatic as well as asymptomatic patient due to its fragile nature and frond like peripheral surface $[8,9]$.

Left sided PFE can cause life-threatening complications whereas right sided PFE usually asymptomatic and rarely cause pulmonary thromboembolism [10], Patients might

present chest pain, which may be anginal or atypical. PFE causing coronary orifice occlusion or embolization may present as acute myocardial infarction [10].

Cerebral embolization present as visual disturbance or transient ischemic .After thoroughly assessment regarding all surgical excision of PFE was done to avoid lethal complication due to embolization .AS surgical excision does not causing significant mortality and morbidity, it is treatment of choice .

\section{Reference:}

1 Remadi JP, Degandt A, Rakotoarivello Z. Cardiac papillary fibroelastoma of the mitral

valve chordae. Heart 2004; 90: 1397.

2.Klarich KW, Enriquez-Sarano M, Gura GM, Edwards WD,Tajik AJ, Seward JB. Papillary fibroelastoma: echocardiographic characteristics for diagnosis and pathologic correlation.

J Am Coll Cardiol 1997;30:784-90.

3. Kurup AN, Tazelaar HD, Edwards WD, Burke AP, Virmani R, Klarich KW, Orszulak TA. Iatrogenic cardiac papillary fibroelastoma fibroelastoma: a study of 12 cases (1990 to 2000). Hum Pathol

2002;33:1165-9.

4. Kim M, Kim SH, Moon SY, Jeong EG, Jung EH, Nam HS, Choi JH, Park K. Native aortic valve thrombosis resembling papillary fibroelastoma. J Cardiovasc Ultrasound 2014;22: 148-50. 
5. Kim SY, Park TH, Lee DY, Lee DH, Cho YR, Kim MH, Kim YD, Hong SH. Papillary fibroelastoma mimicking vegetation of the mitral valve. J Cardiovasc Ultrasound 2012;20:213-5.

6. Liebeskind DS, Buljubasic N, Saver JL. Cardioembolic stroke due to papillary fibroelastoma. J Stroke Cerebrovasc Dis 2001;10:94-5.

7. Gowda RM, Khan IA, Nair CK, Mehta NJ, Vasavada BC,Sacchi TJ. Cardiac papillary fibroelastoma: a comprehensive analysis of 725 cases. Am Heart J 2003;146:404-10.

8. Boodhwani M, Veinot JP, Hendry PJ. Surgical approach to cardiac papillary fibroelastomas. Can J Cardiol 2007;23:301-2.

9. Gopaldas RR, Atluri PV, Blaustein AS, Bakaeen FG, Huh J, Chu D. Papillary fibroelastoma of the aortic valve: operative approaches upon incidental discovery. Tex Heart Inst J 2009;36:160-3.

10. al-Mohammad A, Pambakian H, Young C. Fibroelastoma: case report and review of the literature. Heart 1998;79:301-4.
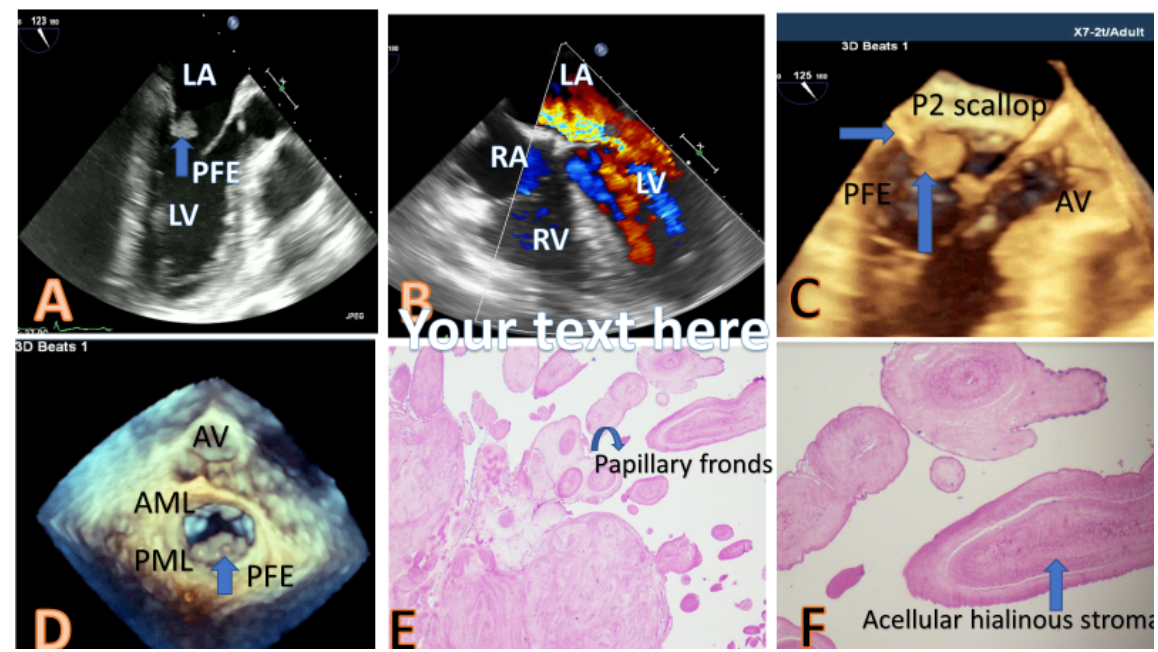

Fig A . Transesophageal 120 degree view shows papillary fibroelastoma (PFE) at P2 scallop; Fig B showing Moderate MR;Fig C modified 3D transesophageal view showed PFE at P2 scallop; Fig D . 3d Transesophageal En face view clearly showed PFE at P2 scallop; Fig E \& F . H\&P revealed a papillary lesion composed of numerous papillary fronds with an acellular fibro-hialinous stroma.

\section{Hosted file}

PFE.pptx available at https://authorea.com/users/377385/articles/494073-papillaryfibroelastoma-of-posterior-mitral-leaflet-confused-as-vegetation-or-calcification 